\title{
Use of a marking rubric and self-assessment to provide feedforward to level 5 undergraduate Sport students: student perceptions, performance and marking efficiency
}

\author{
Edward John Bradley \\ University of Sunderland \\ Steven Anderson \\ University of Sunderland \\ Laurence Eagle \\ University of Wolverhampton
}

\begin{abstract}
The aim of this study was to identify whether Level 5 Sport students find a rubric and selfassessment helpful in providing feedforward on a lab report, and if the rubric improved performance and marking efficiency. A questionnaire was administered to 58 students in order to identify perceptions. Marking time, report grades and classification were compared with the previous year. A significant improvement in the report mark of $7 \%$ $(\rho=0.029)$ from the previous year and an increase in the number of passes in the higher classifications, along with a 25-minute decrease in the mean marking time, were observed. Perceptions of the rubric were generally positive in terms of increasing students' understanding of the assessment. The role of the rubric in the self-assessment process was beneficial, as it enabled students to understand what they were doing well and what they needed to improve. Overall, rubrics should be considered when implementing a laboratory-based practical assessment and report.
\end{abstract}

Keywords: assessment; rubrics; perceptions; feedforward. 


\section{Introduction}

Valuable and effective feedback remains an aspiration of higher education. Feedback for students can emanate from a range of sources and is subject to much academic research and discourse. Educators continue to strive for continuous improvement through managed and documented feedback cycles. The $21^{\text {st }}$ century context continues to impact on how we understand and are able to support learning effectively, with quality feedback processes remaining a key aim of higher education institutions (Nash and Winstone, 2017). Ultimately, if learners are not able to internalise feedback and act upon it, they will remain dependent on others to determine their learning success. The ability to evaluate feedback and act upon it for learning is an essential graduate attribute, as it underpins the capacity to become a self-determined or autonomous learner (Sambell et al., 2013).

\section{Feedforward}

In Hattie's (2009) study, formative feedback was rated as the second most important technique in improving learning with a large effect size $(E S)$ of 0.90 , with feedback in general coming fifth in the list with a medium ES of 0.73 (Hattie, 2009). The capacity to understand feedback has been termed 'feedback literacy' (Sutton, 2012), that is productive engagement with feedback and defined as the 'understandings, capacities and dispositions needed to make sense of information and to use it to enhance work or learning strategies' (Carless and Boud, 2018). Feedback literacy allows students to reflect on their work, forming one of the cornerstones of Kolb's model of experiential learning (Kolb, 1984). It enables students to incorporate teacher commentary more effectively and enhance active learning (Winstone et al., (2017a), and this has been shown to develop as students' progress through university (Carless, 2019a).

For feedback to be useful and facilitate learning, it needs to be timely, accurate and specific to the work (Gibbs and Simpson, 2004). However, the general structure of modules and assessment schedules prevent adequate scope for the utilisation of feedback (Gibbs, 1999), as the majority of feedback, even if timely in nature, will be given on an assignment that is submitted at the end of a module (Higgins et al., 2002). The primary aim of feedback in this circumstance is to highlight issues that the student can act upon in 
future pieces of assessment spanning other modules. In the case of subject-specific feedback, it may not be implemented for six to 12 months after progression to the following academic level. Therefore, design and implementation of an assessment schedule should consider the inclusion of an earlier formative assessment that enables feedback to be provided to the students (Carless, 2019b) so that they are in a position to act and improve work within a module (Black and William, 2009; Quinton and Smallbone, 2010; Sambell et al., 2013), therefore increasing uptake and use of the formative comments (Carless, 2019b).

This process can also be classified as a feedback loop (Hounsell et al., 2008) or cycle (Price and O'Donovan, 2006), in which early guidance and advice is provided that can be implemented as an iterative process and is beneficial for learning. This is likely to promote deep learning, in which ideas and concepts are critically examined and links are formed with existing constructs to develop understanding, as opposed to surface learning of facts and information in an unconnected and passive approach (Marton and Saljo, 1984), enabling students to interact with the assessment in greater detail. Yang and Carless (2013) refer to this as the structural dimension of the feedback triangle, relating to how the feedback is organised and structured.

Feedback which is timely and clearly displayed, and engages the student in the process, is vital for improving student learning. Winstone et al.'s (2017b) study of 31 undergraduate Psychology students identified specific barriers to understanding feedback relating to clarity of terminology and use of jargon, ability to understand how to implement feedback, ownership of feedback, and willingness to engage with feedback. It is important, therefore, that assessment design reflects these key components of feedback. One means of achieving this is through the integration of marking rubrics with a corresponding feedback process.

\section{Rubrics}

Marking rubrics are advocated to produce fair, transparent and consistent marking (QAA, 2006), especially since there is a premium placed on assessment by both academic institutions and students. A rubric, if designed well, provides details of the required level of 
performance across a set of assessment criteria and standards and has been defined by Andrade (2000) as a document that articulates the expectations for an assignment by listing the criteria and describing levels of quality. This has been supported more recently by Jönsson and Panadero (2017), who state that they are a tool for communicating expectations, and assist in judging the quality of work, while Dawson (2017) explains that rubrics should contain 14 design elements including evaluative criteria, levels of quality and appropriate definitions, and accompanying feedback. Similarly, Allen and Tanner (2006) state that a rubric provides scaled levels of achievement against a set of criteria that a learner must exhibit evidence towards.

A range of benefits for both higher education academics and students have been found in the use of rubrics. For rubrics to be most effective, it is argued that student engagement and clarity and appropriateness of language are key factors, both of which require time and effort within, and outside of the classroom. Atkinson and Lim (2013) describe successful application of rubrics - when the barriers to their use are overcome - in the form of positive outcomes for students who go on to improve their next assignment

To increase uptake of marking rubrics, clear benefits to educators must be demonstrated, and this has been documented in the available literature, mainly pertaining to improvements in reliability and consistency. Hornby (2003) reported increased valid and reliable marking, while Cikis and Cil (2009) assert that rubrics minimise arbitrariness and inconsistencies in the marking process. Variability in marking across five tutors was reduced from $15 \%$ to $10 \%$ after the introduction of a rubric in a qualitative Level 7 assessment (Hack, 2013). Assessment marking can be sped up (Allen and Tanner, 2006), as there is less requirement for the marker to provide written feedback across scripts; instead an overview can be provided on the rubric if designed correctly. This is an important point to take forward, as educators may be reluctant to use rubrics due to heavy workloads that limit the time they are able to award to rubric construction. For educators, the benefits include a reported reduction in marking time without having to compromise on the quality of feedback provided. This paper posits that the benefits of using a rubric in conjunction with written feedback outweigh the perceived drawbacks associated with their construction. However, issues do exist in the use of rubrics. These include the simplification of marking, reducing the level of detail in teacher commentary, which may reduce student awareness of the meaning of the feedback as highlighted by Winstone et 
al. (2017b), or create primarily objective feedback through converting a subjective reason to a direct percentage mark for a given section (Kohn, 2006), limiting student application.

\section{Perceptions}

Whilst there is agreement on the pedagogical benefits of utilising rubrics from a teaching perspective, and their use is becoming more common within higher education institutions, less attention has been given to students' approaches to and use of rubrics and how rubrics are perceived by the users. In a study of fourteen undergraduate teacher education students in the United States (Andrade and Du, 2005), the students were positive about rubric use, including understanding the expectations of the teacher, allowing assignment planning, informal self-assessment during assignment composition, and fairness of marking. Similarly, $86 \%$ of 140 Communication Design students in Ghana indicated that an assessment rubric helped their learning on a practical studio-based graphics assignment (Eshun and Osei-Poku, 2013). Wang (2016) reported that 80 Chinese students on an English as a foreign language course indicated that a rubric was useful, as it made them aware of expectations of the writing tasks and check their own work as the tasks progressed.

However, negative perceptions of marking rubrics do exist. These often focus on the students' ability to understand the marking rubric, either suggesting that the criteria are too hard to follow (Koshy, 2009) or are too general (Popham, 1997). Students have remarked that learning how to use marking rubrics, through the teacher including time to explain the marking rubric (Eshun and Osei-Poku, 2013) or formative use of the rubric in a classroom assessment, has removed these negative aspects. If a rubric is provided early in the assessment timeframe, it increases transparency in the process. Reynolds-Keefer (2010) reported that students had a greater understanding of teacher expectations when a rubric was provided and discussed two-weeks prior to submission date. In addition, she linked this to a decrease in anxiety in 13 of the 45 undergraduate students she studied. Similar findings were reported by Andrade and Du (2005) and Panadero et al. (2011). Another common issue was the misconception that it is unnecessary to read the whole rubric (Andrade and Du, 2005) rendering self-assessment ineffective and the rubric a poor formative development tool. 


\section{Aims}

The aim of the study was to understand the perceptions of students using a marking rubric. The main objective was to identify whether a group of Level 5 undergraduate Sport Science students found a marking rubric and self-assessment helpful and positive in providing feedforward on a draft version of a biomechanics lab report. A secondary aim was to identify whether the rubric and self-assessment improved student performance and improved marking efficiency.

\section{Materials and methods}

\section{Design and participants}

A mixed methods approach was utilised in the study. Qualitative information on student perceptions was obtained through a questionnaire, with quantitative data included to identify changes in student performance and summative marking time. These approaches aimed to identify the effect of the implementation of the marking rubrics and selfassessment on student performance in an objective manner (Newby, 2014). Whilst student perceptions are humanistic in nature, as they involve an understanding of human interaction with the assessment task and tool (Cohen et al., 2000), through positivist interpretation of the transcripts and questionnaires by coding and thematic analysis, the identification of common issues relating to the students' use of the marking rubrics and the assessment process can be determined. All Level 5 students $(n=58$; male $=83 \%$; mean \pm SD age $=20 \pm 0.7$ ) on a Sport and Exercise Sciences degree in 2016 participated in the study. Participants were fully informed of the purpose of the study and written consent was obtained. The study was approved by the University of Sunderland institutional ethics group. While the module leader was aware of the group of students whose work they were marking, the questionnaire was fully anonymised in that the staff member did not have access to student responses and data.

\section{Marking rubric}

A marking rubric was developed to assess the performance of students on a Framework for Higher Education Qualifications (FHEQ: UK quality code in higher education to 
maintain academic standards) Level 5 (second year UK undergraduate) Biomechanics module for the task of writing a practical-based lab report. The marking rubric was aligned to the university undergraduate generic marking criteria to distinguish between levels, and specific developmental wording allowed differentiation between grade boundaries within levels. The marking rubric was introduced in the Sport \& Exercise Department as a process by which to improve and standardise marking across modules with the aim of positively influencing student outcomes through feedforward, feedback and general understanding. Space was provided at the end of the rubric for two positive and two developmental comments to allow the marker to ascribe qualitative commentary to the work. The students were introduced to the marking rubric in Week 2 of the module alongside the assignment guidelines. In Week 6, the class attended a 60-minute session on how to use the marking rubric, which included examples of previous work with completed rubrics to aid understanding of the different descriptors and sections on the rubric. The students were instructed to complete a self-assessment of a draft of their report using the rubric and submit both the draft and completed rubric to the online learning environment by Week 9 . The module leader assessed each draft using the same rubric without prior knowledge of the student's assessment to prevent bias. This was returned to the students in Week 10 with instructions to use the module leader assessment and rubric comments for feedforward purposes in finalising their lab report before submission. To achieve this, students were instructed to compare their self-assessment with the module leader rubric to identify how their view of the work differed from that of the module leader. In addition, students were directed to the developmental comments for more detailed instruction on what should be addressed.

\section{Procedure}

A questionnaire was developed based on themes identified in the literature, with the questions designed to determine the level of student use and understanding of the rubric, and to identify the reasons behind their feelings and perceptions of the rubric around the themes of rubric construction, implementation, and feedforward use. The questionnaire was administered in class after final submission of the report, and this achieved a $100 \%$ response rate. The questionnaire comprised 11 questions focussing on the use of and understanding of the rubric and answered using a 1-6 Likert scale (where 1 = strongly disagree, 2 = disagree, 3 = slightly disagree, 4 = slightly agree, 5 = agree, $6=$ strongly 
agree). For all questions, median Likert scores and interquartile ranges were calculated to identify overall student perceptions. The reliability of the questionnaire's 11 questions was evaluated by calculating the Cronbach's Alpha in SPSS v23 (IBM Statistics), with an acoefficient of 0.876 , indicating good internal consistency. These questions were followed by seven open response questions to enable the students to provide qualitative commentary on the rubric. Responses were thematically analysed and common responses identified and collated. To identify whether the marking rubric and self-assessment had a positive effect on student performance, the mean report mark and pass rate were compared with those from the previous year. Summative marking was completed by the module leader, who had created the assessment and rubric. The time taken to mark each assignment was measured using a stopwatch, and marking efficiency was calculated by comparing the mean time taken to mark assignments across each year. Independent Samples t Tests were conducted in SPSS v23 (IBM Statistics) to identify whether significant differences between the two years existed, with a significance level of $\rho<0.05$ set a priori. Magnitude-based inferences were used to identify practically important differences in marks between the year groups. Effect sizes statistics (ES) are presented as Cohen's $d$ (Hopkins et al., 1999) and were calculated using an effect size spreadsheet (https://www.cem.org/effect-size-calculator) from pooled-mean values. Effect sizes were interpreted based on the following criteria: <0.2 trivial, 0.2-0.6 small, 0.6-1.2 moderate, 1.2-2.0 large, $>2.0$ very large (Hopkins, 2004).

\section{Results}

\section{Perceptions of the rubric}

Students' perceptions of the rubric were positive, with the median score for all questions greater than 4 (slightly agree or better) (see Table 1). Student feedback was classified into two distinct themes: 1. rubric construction and use, and 2. rubric as a tool for selfassessment and feedforward.

The majority of students agreed that the rubric clearly defined the criteria needed at each level $(90 \% ; n=52)$ and that the rubric was easy to understand $(92.5 \% ; n=53)$. As a result, $90 \%(n=52)$ of students agreed that the rubric helped them to understand what 
was required in the lab report. This can be observed in the student comments, for example:

I felt the rubric was simpler to understand than the marking schemes as it gave an overview of the section. I used both to help me write the report (S1)

Provided information about what was required to achieve a higher grade and could compare to my own work (S16)

Gives the chance to view the work from a marker's point of view (S2)

Table 1. Student perceptions of the marking rubric.

\begin{tabular}{|c|c|c|c|c|c|c|c|}
\hline Student perception criteria & $\begin{array}{l}\text { Median } \\
\text { response } \\
\text { grade (IQR) }\end{array}$ & $\begin{array}{l}\text { Strongly } \\
\text { Agree } \\
(\%)\end{array}$ & $\begin{array}{l}\text { Agree } \\
(\%)\end{array}$ & $\begin{array}{l}\text { Slightly } \\
\text { Agree } \\
(\%)\end{array}$ & $\begin{array}{l}\text { Slightly } \\
\text { Disagree } \\
(\%)\end{array}$ & $\begin{array}{l}\text { Disagree } \\
(\%)\end{array}$ & $\begin{array}{l}\text { Strongly } \\
\text { Disagree } \\
(\%)\end{array}$ \\
\hline $\begin{array}{l}\text { The rubric uses language that is } \\
\text { easy to understand }\end{array}$ & $5(4-6)$ & 30 & 42.5 & 20 & 2.5 & 2.5 & 2.5 \\
\hline $\begin{array}{l}\text { The rubric clearly defined the } \\
\text { criteria required for each level }\end{array}$ & $5(4.25-5.75)$ & 25 & 50 & 15 & 7.5 & 2.5 & 0 \\
\hline $\begin{array}{l}\text { The rubric helped me } \\
\text { understand what was wanted } \\
\text { on this assignment }\end{array}$ & $5(4.25-5)$ & 15 & 60 & 15 & 7.5 & 2.5 & 0 \\
\hline $\begin{array}{l}\text { I used the rubric while } \\
\text { completing the assignment }\end{array}$ & $4.5(4-6)$ & 32.5 & 17.5 & 30 & 7.5 & 10 & 2.5 \\
\hline $\begin{array}{l}\text { Did the process make you start } \\
\text { your report earlier? }\end{array}$ & $4(2-5)$ & 15 & 20 & 22.5 & 15 & 17.5 & 10 \\
\hline $\begin{array}{l}\text { The rubric is a fair way to } \\
\text { assess assignments }\end{array}$ & $5(4-5)$ & 20 & 52.5 & 22.5 & 2.5 & 2.5 & 0 \\
\hline $\begin{array}{l}\text { The feedback provided on the } \\
\text { rubric was useful }\end{array}$ & $5(4-5.75)$ & 25 & 30 & 30 & 7.5 & 5 & 2.5 \\
\hline $\begin{array}{l}\text { The rubric helped me know } \\
\text { what I was doing well }\end{array}$ & $5(4-5)$ & 15 & 45 & 20 & 12.5 & 5 & 2.5 \\
\hline $\begin{array}{l}\text { The rubric helped me know } \\
\text { what I needed to work on }\end{array}$ & $5(4-5)$ & 17.5 & 42.5 & 22.5 & 12.5 & 2.5 & 2.5 \\
\hline $\begin{array}{l}\text { I know what grade I will } \\
\text { receive for the report }\end{array}$ & $4(3-4)$ & 20 & 35 & 25 & 12.5 & 7.5 & 0 \\
\hline $\begin{array}{l}\text { The rubric helped me to write a } \\
\text { better report }\end{array}$ & $4.5(4-5)$ & 15 & 35 & 35 & 12.5 & 2.5 & 0 \\
\hline
\end{tabular}


However, not all students enjoyed the rubric, and the main criticism focussed on the lack of specificity, with comments such as:

only two feedback points with the rubric you should be able to go through each section of the intro methods etc. and see what needs improvement i.e. more specific feedback instead of an overall indication (S15)

Despite this, $80 \%(n=46)$ of the students agreed that they used the rubric in completing the assignment, and $67.5 \%(n=39)$ agreed that the rubric helped them start the lab report earlier.

\section{Feedforward}

Feedforward was a critical aspect of the assessment process, and $85 \%(n=49)$ of the students acknowledged that the feedback provided on the rubric was useful. The majority also agreed that the rubric helped them understand what they were doing well $(80 \% ; n=$ $46)$ and what they needed to work on $(82.5 \% ; n=47)$. This is reflected in the students' comments:

It just gives you more information and is probably easier to get your head around than comments on your work (S1)

I was able to know where I went wrong and I thought needed improving (S19)

Each section was explained thoroughly on how to achieve that specific mark (S22)

The feedforward enabled students to write a better report $(85 \% ; n=48)$ and, through the self-assessment of the draft, gave an indication of what grade they were likely to receive (80\%; $n=46)$. Supporting comments from the group included:

it helped us to know what we needed to improve on the report therefore our mark/grade (S22)

the self-assessment was very useful in understanding the level of the report (S24) 


\section{Student performance and marking efficiency}

The mean mark for the lab report was $61 \%$, and this was a significant but small improvement of $7 \%(\rho=0.029 ; d=0.41)$ from that of the previous year when no rubric or feedforward was utilised. Additionally, no students failed the assignment compared to 10 the previous year, and the proportion of students achieving a $1^{\text {st }}$ or $2: 1$ grade increased from $43 \%$ to $50 \%$. Mean summative marking time was 13 minutes, a reduction of 25 minutes from the time of 38 minutes the previous year.

\section{Discussion}

The aim of the study was to understand the student perceptions of a rubric when used as self-assessment to provide formative feedforward on a draft version of a Level 5 undergraduate Biomechanics lab report, and to identify whether a marking rubric and selfassessment together improved student performance and marking efficiency.

\section{Student perceptions}

Overall, students found the marking rubric to be a positive tool in the assessment process in undergraduate Sport Science (Table 1). This is consistent with findings reported by Andrade and Du (2005) in undergraduate teacher education, Eshun and Osei-Poku (2013) in a graphic design assignment and Wang (2016) on an English as a foreign language writing task. In general, students indicated that they found the rubric useful when completing the assignment and that it was a fair tool for marking the lab report. Firstly, the students reflected on the rubric as a tool for understanding the assessment. Most students 'slightly agreed' or 'agreed' that the rubric made the assessment criteria clearer and easier to understand and that they knew what was required by the tutor to attain a good level of performance on the assessment. Moni and Moni (2008) reported similar positive remarks from a group of dentistry students in Australia when completing a physiology concept map, as did Eshun and Osei-Poku (2013), who reported that $76 \%$ of students agreed or strongly agreed that a rubric helped explain the subject more clearly. Making the assessment criteria explicit across the levels of achievement enables students to identify the requirements needed for success, and acts as a checklist against which they can selfassess the content of their work (Andrade, 2007). In this way, students can identify the 
appropriate level for their ability and match up their work against the descriptors at that level for each section of the report, as highlighted by Bono et al. (2017), who found that $88.7 \%$ of undergraduate Research Design students agreed or strongly agreed that the rubric 'gave me a better understanding of the assessment criteria'.

As part of the assessment process, students were instructed to complete a selfassessment of a draft version of the lab report ensuring a comparison to the criteria on the rubric was conducted, and this may have been one of the drivers to improved performance compared to the previous year.

The rubric was made available to the class early in the assessment cycle, allowing them to interpret and use the criteria to plan work (Andrade and Du, 2005) at an early stage.

Despite this, students did not perceive that the marking rubric enabled them to start the work earlier. This may be due to the rubric being made available in Week 2 but not explained in detail until Week 6. Researchers have highlighted the benefit of explicitly explaining rubrics (Reynolds-Keefer, 2010), and the inclusion of a session devoted solely to this is seen as good practice and helped in the perception of comprehension and understanding. However, the delay in providing the explanation until week 6 may account for the low perception of the benefit of the rubric in prompting the students to commence the report early. It is therefore suggested that the rubric should be fully explained at the earliest opportunity in an assessment cycle. Secondly, the rubric was used to provide formative feedback during the module, and overall students 'slightly agreed' that the feedback provided was useful, and that this allowed them to know what they had done well and what they needed to work on to improve their final grade.

Whilst the value of using rubrics during the summative assessment process is well established (Andrade and Du, 2007; Eshun and Osei-Poku, 2013), less focus has been given to higher education students' perceptions of the formative feedback provided and the role a marking rubric plays in this process. Wang (2016) found that 54/80 Chinese students utilised the rubric in the 'self-reflection stage' of a writing task, as it aided the generation of self-feedback and was valuable for providing diagnostic information. Considering the importance placed on feedforward as an approach to improving academic performance (Hounsell et al, 2008; Black and William, 2009), the effectiveness of the rubric for enhancing this process, especially in the eyes of the students, is very 
encouraging. Furthermore, there is potential to develop the application of rubrics further in order to enhance their effectiveness, and one such approach is the development of electronic rubrics. Raposo-Rivas and Gallego-Arrufat (2016) implemented an eRubric at two Spanish universities, and the majority of students involved indicated positive learning effects, as the eRubric facilitated peer-learning and the online nature of the rubric is 'handy' and 'prompt'. The option of digitising the rubric, and the effect of integrating it within virtual learning environments, should be examined further, with a focus on student value as the shift to digital approaches increases.

\section{Student performance}

The results of this study imply that introducing the marking rubric to the assignment has produced a significant 7\% improvement in performance, with the mean final mark increasing from $54 \%$ in the previous year to a mean of $61 \%$. There was also a significant $7 \%$ increase in the number of students who received a mark equating to a $1^{\text {st }}$ or $2: 1$ degree grade, equivalent to $50 \%$ of the cohort. The $7 \%$ increase in grade boundary attainment is in line with improvements reported in the literature for university students. For example, Petkov and Petkova (2006) noted a significantly higher mean percentage grade on a short-term information systems project in a group of 20 students who were provided with a project rubric. Hack (2013) also found a significant increase of over $5 \%$ in the average mark of students after the introduction of a rubric to an online learning assessment. The author attributed this to greater standardisation and confidence between markers along with an improved interpretation of the marking criteria by students, especially those in the merit category who showed the greatest level of improvement from the first assignment to the second. In addition, Hafner and Hafner (2003) identified indirect improvements in undergraduate performance when reporting a greater correlation between student and instructor ratings of a rubric-referenced oral biology presentation, assuming that the rubric increased instructor mark level and concurrently student grades increased.

Marking rubrics do not always produce improved performance. Moni and Moni (2008) found a reduction in physiology concept map grade from 8.25 (out of 10) to 7.20 after the introduction of a rubric. However, this was attributed to a poorer academic cohort completing the assignment with a rubric. The reverse could possibly account for the 
improvement in the current study, although no differences in academic standards was evident between the two year-groups, and therefore it is unlikely to be the cause of the mark increase.

It is proposed that the improvement in grades between the two years was not only due to the introduction of the marking rubric, but also its use as a self-assessment tool that improved the feedforward students received. The students were instructed to submit a draft version of the lab report online in Week 8 or 9 of the module, along with a selfassessment of the draft using the rubric provided and explained in Week 6. Feedforward was provided by the module leader with the rubric allowing the student to compare levelness and performance and provide a basis to develop the report for final submission. This approach has shown to improve performance, with a large improvement $(d=1.54)$ in the final score of a child development course assignment reported by Lipnevich et al. (2014). The authors attribute this to the introduction of a marking rubric allowing the students to assess their 'first effort' against the rubric and create changes to a subsequently submitted 'second effort'. This structure is reflected in the approach in the current study, with similar improvements in attainment. This assessment structure creates a formative feedforward approach, as advocated by Hounsell et al. (2008), in contrast to the written annotations within the report utilised the previous year, which the students did not engage with.

Self-assessment is also believed to be beneficial for learning (Topping, 2003) by allowing students to understand the quality of their work, promoting self-reflection and enabling students to learn from their experience (Quinton and Smallbone, 2010). Indeed, Sadler and Good (2006) found that self-grading improved the performance of middle-school students, and that this improvement was greater than when peer-grading was implemented. Rubrics can act as a checklist during self-assessment (Andrade, 2007) whereby students can make judgments about their work (Reddy and Andrade, 2010). If a rubric is well-structured, detailed and thoroughly explained so that the students can fully understand it, it will facilitate the self-assessment process, enabling the identification of good and bad practice in the report. It is therefore suggested that these are key traits for good rubric implementation. 


\section{Marking efficiency}

The result of introducing the marking rubric was a $65 \%$ reduction in the time required to summatively mark each report, with a mean time of 13 minutes. Atkinson and Lim (2013) reported an estimated $40 \%$ reduction in marking time using an online rubric. The single page grid and well-defined level criteria on the rubric allowed the marker to focus on the levelness of each section rather than attempting to allocate marks out of a pre-defined limit per section totalling $100 \%$, the approach that was used in the previous year. Furthermore, the requirement to annotate the report with specific feedback was removed with the marking rubric, as space was allocated at the bottom to provide overall feedback relating to areas that were well-written and areas for improvement. Justification for the reduction in written feedback was based on students' previous reluctance to collect annotated scripts and act on the feedback. With the single page rubric, all students were emailed a copy of the feedforward after submission of the draft and again once summative marking was complete. Thus, it was ensured that all students received timely and accessible feedforward during and after the assessment process, a key factor in understanding feedforward (Weaver, 2006) and enhancing student learning (Gibbs and Simpson, 2004). Caution must be taken when considering such an improvement, as the time taken to mark was considered solely with respect to the summative marking process and did not consider the extra formative process that adds to the assessment workload. However, if the rubric is primarily utilised to mark the final submitted assignment, this improves the process for academic staff.

The substantial saving in marking time may be further enhanced by the development of electronically embedded rubrics that are linked directly to electronic assignment submissions via virtual learning environments. Such an approach was described by Smith et al. (2015), who identified the efficiency of an online rubric that improved ease of marking and the release of grades and rubric feedback to a cohort of 300 students. While few studies report the effect of using rubrics on marking time, it is likely that teachers and lecturers will be happy to adopt them into normal practice if there is evidence that they improve marking efficiency and demonstrate a personal benefit within the assessment procedure. 


\section{Limitations}

While comparisons of student achievement were conducted between academic years, improvements in performance may be due to comparing different cohorts, the second of which may be stronger academically or display a higher level of motivation and achievement. While differing academic standards may have resulted in the improvement in marks, it is assumed that the likelihood of this is decreased due to the broadly similar academic profiles of the cohorts at the end of their first year of study. However, the study would have been strengthened if two groups in the cohort were assessed, with and without the marking rubric implementation, although this was not possible at the time due to the limitations placed on the modification of assessment as per institutional regulations.

Additionally, student perceptions of the rubric were only collected in their second year, and no comparison could be made with perceptions of the assessment process when a rubric was not included. Potentially students identified with the university's generic criteria and the scoring sheet used at the time and perceived these in the same manner as the new rubric. However, the authors believe the rubric was a better tool to assist the students, and the improvements are likely to have been as a result of a change in the assessment process and the introduction of self-assessment and formative feedforward.

Student perceptions were collected via a questionnaire that required responses to a series of set questions on a Likert scale with seven pre-set questions to provide qualitative commentary. Such an approach has been previously utilised by Quinton and Smallbone (2010) and Eshun and Osei-Poku (2013). This elicited useful information in an efficient manner; it was, however, restricted in its detail. Amendments to the questionnaire to allow open-ended responses alongside the fixed questions would allow students to expand on the reasons for their answers and feelings about the rubric. Also, Andrade and Du (2005) included group interviews, and Moni and Moni (2008) used filming of class interactions as further methods for capturing perceptions, although similar findings were discovered using all methods and the approach used in the current study was considered appropriate. 


\section{Conclusions}

This paper reports on the implementation of a rubric to facilitate self-assessment and provide formative feedback on a Level 5 sports science lab report. The assessment process resulted in a significantly improved mean mark, an increased pass rate in the upper degree classifications and reduced report marking time by the module leader. Student perceptions of the marking rubric were generally positive in that is was seen to clearly define the criteria needed to succeed and increase understanding of what was required in the assessment. It was also agreed that the role of the rubric in the selfassessment and feedforward process was beneficial, as it enabled the students to understand what they were doing well and what they needed to work on. Overall, marking rubrics are an important tool in improving academic performance and should be considered when implementing a laboratory-based practical assessment and report.

\section{Ethical approval}

Ethical approval was obtained from the University of Sunderland institutional Ethics Committee. All students provided written consent to participate in the study.

\section{References}

Allen, D. and Tanner, K. (2006) 'Rubrics: Tools for making learning goals and evaluation criteria explicit for both teachers and learners', CBE-Life Sciences Education, 5(3), pp.197-203.

Andrade, H. (2000) 'Using rubrics to promote thinking and learning', Educational Leadership, 57(5), pp.13-18.

Andrade, H. (2007) 'Self-assessment through rubrics', Educational Leadership, 64(5), pp.60-63. 
Andrade, H. and Du, Y. (2005) 'Student perspectives on rubric-referenced assessment', Practical Assessment, Research \& Evaluation, 10(3), pp.1-11.

Atkinson, D. and Lim, S.L. (2013) 'Improving assessment process in higher education: student and teacher perceptions of the effectiveness of a rubric embedded in a LMS', Australasian Journal of Educational Technology, 29(5), pp.651-666.

Black, P. and William, D. (2009) 'Developing the theory of formative assessment', Educational Assessment Evaluation and Accountability, 21(1), pp.5-31.

Bono, R., Núñez-Peña, M. and Suárez-Pellicioni, M. (2017) 'Rubrics use and in-class feedback in higher education: students' perceptions and their effect on academic achievement', Proceedings of the 3rd International Conference on Higher Education Advances. Editorial Universitat Politècnica de València, pp.338-346.

Carless, D. (2019a). 'Longitudinal perspectives on students' experiences of feedback: a need for teacher-student partnerships', Higher Education Research \& Development, 39(3), pp. 425-438.

Carless, D. (2019b) 'Feedback loops and the longer term: Towards feedback spirals', Assessment \& Evaluation in Higher Education, 44(5), pp.705-714.

Carless, D. and Boud, D. (2018) 'The development of student feedback literacy: enabling uptake of feedback', Assessment \& Evaluation in Higher Education, 43(8), pp.13151325.

Cikis, S. and Cil, E. (2009) 'Problematization of assessment in the architectural design education: first year as a case study', Procedia Social and Behavioral Sciences, 1(1), pp.2103-2110.

Cohen, L., Manion, L. and Morrison, K. (2000) Research Methods in Education. $2^{\text {nd }}$ edn. Abingdon, UK: RoutledgeFalmer. 
Dawson, P. (2017) 'Assessment rubrics: towards clearer and more replicable design, research and practice', Assessment and Education in Higher Education, 42(3), pp.347-360.

Eshun, E.F. and Osei-Poku, P. (2013) 'Design students perspectives on assessment rubric in studio-based learning', Journal of University Teaching \& Learning Practice 10(1), pp.1-13.

Hattie, J.A.C. (2009) Visible learning: a synthesis of 800+ meta-analyses on achievement. London: Routledge.

Gibbs, G. (1999) 'Using assessment strategically to change the way students learn', in Brown, S. and Glasner, A. (eds.) Assessment matters in higher education: choosing and using diverse approaches. Buckingham: SRHE and Open University Press.

Gibbs, G. and Simpson, C. (2004) 'Conditions under which assessment supports students' learning', Learning and Teaching in Higher Education, 1(1), pp.3-31.

Hack, C. (2013) Using rubrics to improve marking reliability and to clarify good performance. York: Higher Education Authority.

Hafner, J.C. and Hafner, P.M. (2003) 'Quantitative analysis of the rubric as an assessment tool: an empirical study of student peer-group rating', International Journal of Science Education, 25(12), pp.1509-1528.

Higgins, R., Hartley, P. and Skelton, A. (2002) 'The conscientious consumer: reconsidering the role of assessment feedback in student learning', Studies in Higher Education 27(1), pp.53-64.

Hopkins, W. (2004). 'How to interpret changes in athletic performance tests', Sportsscience, 8, pp.1-7. 
Hopkins, W.G., Marshall, S.W., Batterham, A.M. and Hanin, J. (1999) 'Progressive statistics for studies in sports medicine and exercise science', Medicine \& Science in Sports \& Exercise, 41(1), pp.3-13.

Hornby, W. (2003) 'Assessing using grade-related criteria: a single currency for universities?', Assessment and Evaluation in Higher Education, 28(4), pp.435-454.

Hounsell, D., McCune, V., Hounsell, J. and Litjens, J. (2008) 'The quality of guidance and feedback to students', Higher Education Research and Development, 27(1), pp.5567.

Jönsson, A. and Panadero, E. (2017) 'The use and design of rubrics to support AfL', in Carless, D., Bridges, S., Chan, C. and Glofcheski, R. (eds.), Scaling up Assessment for Learning in Higher Education. Dordrecht: Springer.

Kohn, A. (2006) 'The trouble with rubrics', English Journal. 95(4).

Kolb, D.A. (1984) Experiential Learning. Englewood Cliffs, NJ.: Prentice Hall.

Koshy, S. (2009) 'Using marking criteria to improve learning: an evaluation of student perceptions', Journal of Systemics, Cybernetics and Informatics, 7(1), pp.72-76.

Lipnevich, A.A., McCallen, L.N., Miles, K.P. and Smith, J.K. (2014) 'Mind the gap! Students' use of exemplars and detailed rubrics as formative assessment', Instructional Science, 42, pp.539-559.

Marton, F. and Saljo, R. (1984) 'Approaches to learning', in Marton, F., Hounsell, D. and Entwistle, N. (eds.), The experience of learning. Edinburgh: Scottish Academic Press.

Moni, R.W. and Moni, K.B. (2008). 'Student perceptions and use of an assessment rubric for group concept map in physiology', Advances in Physiology Education 32(1), pp.47-54. 
Nash, R.A. and Winstone, N.E. (2017) 'Responsibility-sharing in the giving and receiving of assessment feedback', Frontiers in Psychology, 8, p.1519.

Newby, P. (2014) Research Methods for Education. $2^{\text {nd }}$ edn. London, UK: Routledge.

Panadero, E., Alonso-Tapia, J. and Huertas, J.A. (2011) 'Rubrics and self-assessment scripts effects on self-regulation, learning and self-efficacy in secondary education', Learning and Individual Differences, 22(6), pp.806-813.

Petkov, D. and Petkova, O. (2006) 'Development of scoring rubrics for IS projects as an assessment tool', Issues in Informing Science and Information Technology, 3, pp.499-510.

Popham, J.W. (1997) 'What's wrong - and what's right - with rubrics', Educational Leadership, 55 (2), pp.72-75.

Price, M. and O'Donovan, B. (2006) 'Improving performance through enhancing student understanding of criteria and standards', in Bryan, C. and Clegg, S. (eds.), Innovative Assessment in Higher Education. Routledge: New York.

Quality Assurance Agency for Higher Education. (2006). Outcomes from institutional audit: Assessment of students, QAA 097. Available at: https://dera.ioe.ac.uk/9638/1/Assessmentofstudents.pdf (Accessed: 17 June 2020).

Quinton, S and Smallbone, T. (2010) 'Feeding forward: using feedback to promote student reflection and learning - a teaching model', Innovations in Education and Teaching International, 47 (1), pp.125-135.

Raposo-Rivas, M. and Gallego-Arrufat, M.J. (2016) 'University students' perceptions of electronic rubric-based assessment', Digital Education Review, 30, pp.221-233.

Reddy, Y.M. and Andrade, H. (2010) 'A review of rubric use in higher education', Assessment and Evaluation in Higher Education, 35(4), pp.435-448. 
Reynolds-Keefer, L. (2010) 'Rubric-referenced assessment in teacher preparation: an opportunity to learn by using', Practical Assessment Research and Evaluation, 15(8), pp. 1-9.

Sadler, P.M. and Good, E. (2006) 'The impact of self- and peer-grading on student learning', Educational Assessment ,11(1), pp.1-31.

Sambell, K., McDowell, L. and Montgomery, C. (2013). Assessment for Learning in Higher Education. London: Routledge.

Smith, P., Blooma, M.J. and Kurian, J. (2015) 'A conceptual framework to assess effectiveness of rubric tool', Australasian Conference on Information Systems.

Sutton, P. (2012) 'Conceptualizing feedback literacy: Knowing, being, and acting', Innovations in Education and Teaching International, 49(1), pp.31-40.

Topping, K. (2003) 'Self and peer assessment in school and university: reliability, validity and utility', in Segers, M., Dochy, F. and Cascallar, E. (eds.), Optimizing new modes of assessment: in search of qualities and standards. Dordrecht: Kluwer Academic Publishers.

Wang, W. (2016) 'Using rubrics in student self-assessment: student perceptions in the English as a foreign language writing context', Assessment and Education in Higher Education 42(8), pp.1280-1292.

Weaver, M. (2006) 'Do students value feedback? Student perceptions of tutors' written responses', Assessment and Education in Higher Education, 31(3), pp.379-394.

Winstone, N.E., Nash, R.A., Parker, M. and Rowntree, J. (2017a) 'Supporting learners' agentic engagement with feedback: a systematic review and taxonomy of recipience processes', Educational Psychologist, 52(1), pp.17-37. 
Winstone, N.E., Nash, R.A., Rowntree, J, and Parker, M. (2017b). 'It'd be useful, but I wouldn't use it': barriers to university students' feedback seeking and recipience', Studies in Higher Education, 42(11), pp.2026-2041.

Yang, M. and Carless, D. (2013) 'The feedback triangle and the enhancement of dialogic feedback process', Teaching in Higher Education, 18(3), pp.285-297.

\section{Author details}

Eddie Bradley is a Senior Lecturer in Biomechanics in the Faculty of Health Sciences \& Wellbeing at the University of Sunderland, specialising in biomechanics and performance analysis. His research interests are in developing and implementing pedagogic tools to enhance student attainment, and understanding how students are impacted by educational progression. He is a Fellow of the Higher Education Academy and a BASES Accredited Sport \& Exercise Scientist.

Steven Anderson is a Senior Lecturer in Physical Education at the University of Sunderland, specialising in physical education and the health of young people. His research interests are in implementing pedagogic tools to enhance student attainment and development. He is a Fellow of the Higher Education Academy.

Laurence Eagle is a Principal Lecturer and Head of Quality, Standards and Enhancement in the Faculty of Education, Health \& Wellbeing at the University of Wolverhampton, specialising in postgraduate HE educator training. His research interests are in curriculum development and information technology to enhance student experiences. He is a Senior Fellow of the Higher Education Academy. 